\title{
Alternativas a la economía y al desarrollo desde las epistemologías del Sur y algunas nuevas visiones del mundo
}

José Andrés Fuentes González*

Doctorando en Estudios Medioambientales, Universidad Pablo de Olavide. Director ejecutivo de Yomol A tel, México.

Correo electrónico:

jfuentes@capeltic.org

Recibido: 17 de enero del 2016

Aceptado: 31 de mayo del 2016

Cómo citar este artículo: Fuentes-González, J. A. (2016). Alternativas a la economía y al desarrollo desde las epistemologías del Sur y algunas nuevas visiones del mundo. Cooperativismo \& Desarrollo, 24(109), xx-xx. doi: 10.16925/co.v24i109.1504

\section{Resumen}

Propósito: este artículo se enmarca en una lucha regional por la construcción de autonomías, de espacios liberados, y en una defensa del territorio y de nuestra madre tierra. La búsqueda de alternativas en estos tiempos de crisis global es urgente. Pero no necesitamos alternativas, sino un nuevo modo de producción de conocimiento, es decir, de un pensamiento alternativo de las alternativas. Descripción: en este artículo expondremos el caso de Yomol A'tel (grupo de cooperativas y empresas de economía solidaria en Chiapas, México) en el cual se intenta basarse en la cosmovisión indígena tseltal para construir otras formas de hacer economía y de entender el trabajo y la producción. Punto de vista: La economía, el desarrollo y todas las instituciones de la sociedad industrial son hijas del ego moderno: este es el que está en crisis y en cuestión. Realizar nuestros análisis e investigaciones desde premisas epistémicas distintas nos llevará a diferentes conclusiones; la realidad responde según el lenguaje en el que se le pregunte. Conclusiones: tanto las epistemologías del Sur como otras nuevas visiones del mundo pueden entrar en un diálogo de saberes y ser la base para la construcción de un nueva y pertinente forma de conocimiento.

Palabras clave: crisis civilizatoria, Chiapas, economía solidaria, epistemologías del sur, saberes indígenas, vida buena. 


\title{
Economic and development alternatives from epistemologies of the South and certain new worldviews
}

\begin{abstract}
Purpose: This article is written in the context of a regional struggle for the construction of autonomies, liberated spaces, and a defense of territory and our Mother Earth. The search for alternatives in these times of global crisis is urgent. However, we do not need alternatives but rather a new mode of knowledge production, i.e., an alternative way of thinking about alternatives. Description: In this article, we will discuss the case of Yomol A'tel (a group of solidarity economy cooperatives and enterprises in Chiapas, Mexico), which seeks to base itself on the Tzeltal indigenous worldview to find other ways of doing economics and of understanding work and production. Viewpoint: The economy, development, and all institutions of industrial society are daughters of the modern ego: it is this that is in crisis and in question. Conducting our analyses and research from different epistemic premises will lead us to distinct conclusions; reality shifts depending on the language used to inquire about it. Conclusions: Both epistemologies of the South and other new worldviews can enter into a dialogue of knowledges and be the basis for the construction of a new and relevant way of knowing.
\end{abstract}

Keywords: civilizational crisis, Chiapas, solidarity economy, epistemologies of the South, indigenous knowledge, good living

\section{Alternativas à economia e ao desenvolvimento a partir das epistemologias do Sul e algumas novas visões do mundo}

\section{Resumo}

Propósito: este artigo é parte de uma luta regional pela construção de autonomias, de espaços liberados, e de uma defesa do território e de nossa mãe terra. A busca de alternativas nesses tempos de crise global é urgente. Mas não precisamos de alternativas, e sim de um novo modo de produção de conhecimento, isto é, de um pensamento alternativo das alternativas. Descrição: neste artigo exporemos o caso de Yomol A’tel (grupo de cooperativas e empresas de economia solidária em Chiapas, México) o qual procura basear-se na cosmovisão indígena tseltal para construir outras formas de fazer economia e de entender o trabalho e a produção. Ponto de vista: A economia, o desenvolvimento e todas as instituições da sociedade industrial são filhas do ego moderno: isso é o que está em crise e em questão. Realizar nossas análises e pesquisas a partir de premissas epistêmicas distintas leva-nos a diferentes conclusões; a realidade responde de acordo com a linguagem em que lhe for perguntada. Conclusões: tanto as epistemologias do Sul quanto outras novas visões do mundo podem entrar num diálogo de saberes e ser a base para a construção de uma nova e pertinente forma de conhecimento.

Palavras-chave: crise civilizatória, Chiapas, economia solidária, epistemologias do sul, saberes indígenas, vida boa. 


\section{¿De dónde partimos?}

Este artículo intenta poner en diálogo algunos de los aportes de las epistemologías del Sur y de las nuevas visiones del mundo - emanadas de algunas ramas de la ciencia moderna- para repensar - o "sentipensar", más bien - ideas pertinentes para afrontar la actual crisis global a la que nos ha traído esta sociedad industrial. Previamente expondremos algunas bases de la cosmovisión moderna que sirven de sustento a las ideas de economía y desarrollo como parte del ejercicio decolonial al que nos invitan en este número. Finalmente plantearemos ideas sobre cómo este ejercicio puede tomar forma en experiencias concretas; en este caso la del grupo cooperativo Yomol A'tel con sede en la Selva Norte de Chiapas, México.

Sería necio seguir argumentando sobre la gravedad y profundidad de esta crisis civilizatoria y en cómo la economía hegemónica - la convencional de raíz neoclásica- y el imperativo del desarrollo están terminando con la diversidad y la naturaleza de este mundo, lo que genera destrucción y muerte a su paso. Ambos han cumplido su ciclo histórico y están destinados a estudiarse como en la arqueología, en pasado (Sachs, 1990). El proyecto civilizatorio industrial tendrá fin pronto, ya sea por un cambio en la conciencia planetaria, ya sea por una catástrofe ambiental, la destrucción y la muerte, que, si habrán de ser, serán.

Mientras más nos acercamos al final de nuestra etapa evolutiva, más disfuncional se torna el sistema y el ego que lo dirige; así como se vuelve disfuncional la oruga antes de convertirse en mariposa (Tolle, 2005). Pero el éxito de esta transformación no está asegurado, ni mucho menos. Dependerá de que se abra la oportunidad de cambiar los axiomas y los puntos de partida sobre los cuales normalmente comprendemos el mundo y nos entendemos. Estas son transformaciones existenciales que nos pueden llevar a descubrir nuevas posibilidades de realidad $y$, por tanto a modificar todas las áreas de nuestros quehaceres humanos.

Como explica Morin, "[...] uno de los aspectos del problema planetario es que las soluciones intelectuales, científicas o filosóficas a las que habitualmente se recurre constituyen ellas mismas los problemas más graves y más urgentes a resolver" (1993, p. 69). Es por tanto evidente la necesidad de descolonizar nuestras mentes y nuestros corazones. Para esto, como explica Marañón-Pimentel (2012), debemos comenzar por deconstruir las categorías de modernidad y de colonialidad en sus bases teóricas y epistemológicas. Así se verán las rupturas del proyecto civilizatorio moderno y nos dará pistas para guiar la construcción de alternativas.

En este camino es inevitable que las preguntas académicas se conviertan en existenciales. Profundizar en estas nos lleva a cuestionar los fundamentos cosmogónicos sobre los cuales hemos construido una interpretación de la realidad y nuestra relación con el mundo. Llamemos a esto paradigma epistémico, cosmovisión, cosmos-ser, no importa: hablamos de las bases culturales más profundas a partir de las cuales interpretamos y, por tanto, experimentamos el mundo. Desde aquí pretendemos hablar para empezar a imaginar otras posibilidades de realidad.

\section{La economía, el desarrollo y el ego moderno}

No pretendemos hacer un recuento sobre la crítica a la economía convencional y al desarrollo. Mucho ha sido dicho ya por voces extraordinarias como las de Iván Illich (1973, 1992), Gustavo Esteva (1992, 2009 , 2013b), Arturo Escobar (1995), Boaventura de Sousa (Santos, 2000) o Enrique Leff (1996). Es por esto que solo entraremos en algunas cuestiones clave que nos permitan enmarcar de mejor manera el diálogo intercultural que intentaremos construir más adelante.

Años de trabajo crítico desde la economía política nos han mostrado cómo las "leyes económicas" no son más que invenciones lógicas que ayudaron a apoyar proyectos políticos de hace 300 años (Esteva, 2013b). La economía convencional, con una envidiable elegancia matemática, ha reducido la complejidad del mundo y ha obtenido resultados de una lógica impecable, pero sin relación con la realidad (Pigem, 2013). Es muy sospechoso que la "ciencia" que más impacta nuestras vidas a nivel social sea tan pobre epistemológicamente hablando. La economía convencional es la que sustenta los argumentos, análisis, conclusiones y decisiones que permiten perpetuar el statu quo del orden mundial o del sistema-mundo.

Por poner un ejemplo, la escasez - el "problema económico" por excelencia- solo puede entenderse si se acepta como punto de partida que los deseos materiales son infinitos (bajo este supuesto, claro, todo es escaso). Se asume también un ser humano (y al mundo animal también) egoísta e individualista, que rige sus relaciones a través de la competencia y la ganancia. Esto, por supuesto, está lejos de ser algo "natural" en los humanos - si algo como tal existiera-Capra (1982) y Esteva (2013b) explican cómo en 
muchas culturas estos comportamientos se veían, y se ven, como locura, enfermedad o inmoralidad.

Por su parte, la tecnocracia intenta convencernos de que a través de la economía verde podremos salir del problema en el que estamos. No entraremos en explicar el despropósito de un proyecto que pretende salir del hoyo cavando más profundo. Ya desde los años setenta Georgescu-Roegen (2007) —vía un análisis a través de la termodinámica- e Iván Illich (1973) - argumentando sobre los devastadores efectos que la sobreproducción de servicios traerá- han demostrado la inviabilidad de estas propuestas.

El problema al que se enfrenta la economía no es económico ni social: es epistemológico y político. Sin un replanteamiento de su interpretación materialista y parcial de la realidad, del ser humano y de su sentido de ser en el mundo, le seguirá siendo imposible - aunque pasen otros tres siglos-comprender la realidad que pretende estudiar.

Ahora bien, el desarrollo, como la economía, se constituyó como otra institución del paradigma moderno, y sus medios - el capital y la industrialización - resultaron complementarios a los de la economía convencional. No importa si los medios y las razones eran capitalistas o socialistas, el fin - el desarrollo - estaba determinado, y el medio - la economía convencional- también.

Gilbert Rist (2002) explica cómo la importación - de la biología- del término "desarrollo" dejó de lado la idea de decadencia - es decir, la visión cíclica y sistémica de los sistemas vivos-, y se favoreció una lectura de la historia como un proceso lineal evolutivo: la idea de "progreso" como camino universal que implica ir de peor a mejor ¿Quién podría oponerse a esta? Pocos parecen caer en cuenta que el desarrollo "Es un adjetivo comparativo cuya base de sustentación es el supuesto, muy occidental pero inaceptable e indemostrable, de la unidad, homogeneidad y evolución lineal del mundo" (Esteva, 1992, p. 59).

Desde Truman, cuando en 1949, anunció su programa para ayudar a los países subdesarrollados, hasta Amartya Sen, que sesenta años después aboga por una visión humana del desarrollo, la aparente ley universal del progreso sigue siendo la aspiración a ser desarrollado, y esta es el motor de las sociedades industriales (Illich, 1992). Esta norma se materializa en "recomendaciones" neoliberalistas dictadas en el Norte e impuestas en el resto del mundo por las organizaciones globales para el desarrollo (BM, FMI, ONU, PNUD, OIT, etc.).
La corriente postdesarrollista y de la descolonialidad del poder han dado cuenta de cómo este desarrollismo ha tenido una virulencia colonizadora. $\mathrm{Su}$ expansión e imposición global homogenizó y despreció las demás formas de ser en el mundo - especialmente a las culturas no modernas- ocasionando un epistemicidio sin precedentes.

No conforme con el atentado contra la diversidad cultural de la humanidad que representa, el proyecto civilizatorio que promueve - el de una sociedad industrializada - es inviable ambiental y socialmente. Simplemente porque la Tierra no tiene capacidad para soportar a toda la población con el estilo de vida de los países del Norte (Leff, 1996). El argumento generalmente utilizado para defender lo contrario consiste en la esperanza de que la tecnología lo resuelva todo. Puede que sí, pero puede que no, y lo que está en juego es sencillamente el equilibrio dinámico de la Tierra - y con esto, la forma de vida humana en sociedad como la conocemos.

Aun así, este proyecto desarrollista tampoco está cumpliendo con su promesa de hacer más felices a las personas. Así lo demuestra el Happy Planet Index (2012) en el cual se ubica a Noruega como el país desarrollado más alto en su lista, apareciendo en el puesto número 29. Esto implicaría, según este análisis, que los 28 países más felices según este índice son subdesarrollados. Hay muy pocos estudios serios sobre la felicidad humana, pero en los pocos que se han realizado, las sociedades industriales no parecen salir mejor que las sociedades "no desarrolladas". Entonces, ¿por qué tanta insistencia en el imperativo del desarrollo? ¿No se trataba una cuestión de vivir bien y de ser felices?

La visión occidental colonizadora se mantiene y defiende, aunque se disfrace con discursos paliativos. Es así como desde la bienintencionada corriente de los estudios sobre el desarrollo se han encontrado un sinfín de adjetivos para ponerle al concepto y así acotarlo, mejorarlo, paliarlo o simplemente salvarlo. A saber, podemos documentar:

1. Desarrollo "propio".

2. "Etno" desarrollo.

3. Desarrollo "de abajo hacia arriba".

4. Desarrollo "participativo".

5. "Otro" desarrollo.

6. Desarrollo "sostenido".

7. Desarrollo "sustentable" o "sostenible".

8. Desarrollo "endógeno".

9. Desarrollo "local". 
10. Desarrollo "económico".

11. Desarrollo "rural sustentable".

12. Desarrollo "alternativo".

13. Desarrollo "integrado".

14. Desarrollo "humano".

15. Desarrollo "a escala humana".

Ante este panorama ¿vamos a seguir buscando cuál es el adjetivo correcto y la forma verdadera que debe adoptar el desarrollo? ¿Vamos a seguir intentando salvar la ilusión del desarrollo, que no hace más felices a las personas y que es insostenible ambiental y socialmente?, ¿o vamos a permitirnos mirar más allá e imaginar otras posibilidades de realidad?

Hay conceptos e ideas que tenemos que superar para imaginar un posible futuro sustentable, como las nociones de economía y desarrollo, y otras más profundas como la idea de necesidad, de ver a la naturaleza como recurso y la misma separación entre sujeto y objeto; estas nociones son propias de esta cosmovisión moderno-industrial.

Iván Illich (1992) explica en detalle cómo no hay indicios de que antes de la época del desarrollo la humanidad haya experimentado algo similar a lo que hoy damos por descontado como necesidades básicas. Bajo una lógica de "siempre más" del progreso lineal, de competencia, de individualismo y de escasez, surge el homo miserabilis y del homo ceconomicus siempre insatisfecho y deseando más cosas. Si no eliminamos esta idea de necesidad miserable - definida a partir de la falta de algo- será difícil caminar hacia las ideas de la vida buena que más adelante plantearemos.

Pieza clave para entender la devastación ambiental que se da día a día es la comprensión moderna-científica e instrumentalizadora de la naturaleza. A partir de la ilusión de que hay una separación entre sujeto y objeto nos hemos apartado de la naturaleza, y entonces "entendemos" que existe una sociedad y una naturaleza como formas aisladas y que se comunican. Lejos de entender una interrelación sagrada - o no separación - con la Madre Tierra, se le ve como un conjunto de "recursos naturales" - recurso entendido como medio que sirve para algo más-, ya no digamos la crueldad de llamarle "capital natural". Como nombramos las cosas dice mucho del paradigma de nuestro pensamiento.

Si nuestro marco interpretativo de la realidad no se modifica radicalmente, difícilmente podemos aspirar a construir una sociedad sustentable. Este ego moderno que encarnamos y está basado en esta separación, se siente un fragmento individual aislado del resto del mundo, en un universo hostil. De su miedo surge la necesidad de certeza, de dominio y competencia, de cuantificar y clasificar (Pigem, 2009, p. 88). El individualismo atomista de John Locke heredó la idea de los humanos que son competitivos y egoístas por naturaleza (Capra, 1982); esa misma concepción refleja la economía, el comercio, el desarrollo, así como nuestras relaciones sociales y con la naturaleza.

Identifico tres fuentes - que no pretenden ser exhaustivas- de este ego moderno. En primer lugar, hay una separación entre el observador y lo observado . Esta idea de separación es común a todas las culturas humanas: en unas más pronunciada que otras, y proviene de tiempos inmemoriales. En el budismo a esto se le llama avidya, una tendencia ilusoria de dividir el mundo en cosas individuales y separadas, incluyéndonos como observadores (Capra, 1975).

Posteriormente este ego moderno se alimentó del pensamiento abstracto a partir de conceptos introducidos por el Occidente griego, bajo una idea atomista de la realidad; esto fortaleció la idea de separación entre el sujeto y objeto, e incorporó la noción de objetividad. Antes, como explica Feyerabend (1984), los dioses, hombres y hechos cosmológicos no se caracterizaban a través de definiciones o teorías, sino por medio de narraciones. Este método subjetivo es más apropiado para iluminar un objeto desde muchos aspectos y pone de manifiesto que la información no puede ser completa ni objetiva.

Por último, la expansión imperial del mundo europeo y de la modernidad a partir del siglo xvi. Este proceso, del cual deriva la sociedad industrial y el concepto de desarrollo, se ha globalizado y ha ocupado la mayor parte del planeta. Esta cosmovisión moderna parte del dualismo excluyente cartesiano - que al contrario de la polaridad fundacional de las cosmovisiones mesoamericanas y orientales (que adelante expondremos), separa lo uno y lo múltiple-, y así se "separa" de la realidad (sujeto-objeto) y la mira "objetivamente" en fragmentos, incluso a sí misma (con esta ruptura de mente y cuerpo). Esta cosmovisión moderno-industrial que prioriza la velocidad, el crecimiento y la eficiencia, junto con su capacidad de manipular la naturaleza le ha dado un giro aniquilador a esta historia.

Este ego moderno vive en nosotros y a través de nosotros. Esta cosmovisión moderna permea prácticamente todas las instituciones modernas — desde el sistema educativo o de transporte hasta la ciencia y la democracia. A Gustavo Esteva (2009) le gusta 
recordar cómo Gandhi consideraba a la civilización occidental como un mal curable. Es evidente ya que este pensamiento cartesiano ha durado más que su utilidad y que es tiempo de buscar alternativas.

\section{Algunas nuevas - y no tan nuevas- visiones del mundo}

Existen diversas corrientes epistémicas en la tradición científica que intentan trascender el paradigma cartesiano. Entre estas encontramos la transdisciplinaridad y el pensamiento complejo, el holismo, la física cuántica y las nuevas concepciones de la vida en la biología y la teoría de sistemas. No pretendemos hacer un repaso de estas propuestas sino solo exponer algunas ideas relevantes.

Fritjof Capra (1996) explica cómo en la física y la biología se ha constatado que los sistemas son totalidades que carecen de significado como entidades aisladas. Las partículas subatómicas, por ejemplo, únicamente pueden ser entendidas como relaciones (que incluyen al observador y al proceso de medición); esto implica que las partículas - las cosas - no son cosas, sino interconexiones y solo así pueden ser entendidas y explicadas.

Si esto aplica para los objetos del mundo, mucho más evidente es para los procesos. Así, las crisis económica, ambiental, política, cultural, epistemológica, etc. no pueden ser entendidas por separado. Es necio seguir pensando la pobreza como un problema económico o la sustentabilidad como una cuestión ambiental. Todos los eventos son transdisciplinares o, más bien, adisciplinares: las disciplinas son la ficción.

Asumir esto implica reconocer que la materialidad existente, desde los microbios hasta las galaxias, forma una red de procesos multidimensionales interconectados. Tolle (2005) explica cómo nuestra percepción - a través de los sentidos y la mente racionalizadora - y nuestro torrente de pensamientos compulsivos son lo que nos apartan e impiden percibir esa unidad de todas las cosas. En cuanto se logra percibir sin interpretar - como lo saben muchas filosofías orientales - se puede acceder a esa conexión más profunda con el todo.

Maturana y Varela (1979) definen el término "autopoiesis" para definir un sistema capaz de reproducirse y mantenerse por sí mismo. Esto implica una concepción del mundo - y de la vida- ecológica, más que una mecanicista y positivista. La comprensión de la vida es mucho más compleja de lo que se había imaginado (Capra, 1996) y las posibilidades de entender, entre otras cosas, la vida, adquieren nuevas posibilidades de realidad. Así podemos imaginar a Gaia, como sistema vivo, nuestra Madre Tierra.

Abrirnos a estas nuevas posibilidades de entender el mundo y de existencia de las cosas, la vida en este caso permite imaginar ir más allá, “Es el sistema solar una red autopoiésica? ¿Y la galaxia? ¿Y qué decir del universo como un todo? ¿Está vivo el universo? (Capra, 1996, p. 228) ${ }^{1}$.

Ahora bien, regresemos de las escalas galácticas a lo más pequeño que conocemos, la escala subatómica que estudia la física cuántica. Niels Bohr -uno de los más destacados físicos del s. xx y quien fuera uno de los primeros en defender que ningún fenómeno existe hasta que es un fenómeno observadoexplicaba las profundas implicaciones epistémicas y ontológicas de todo esto afirmando que "quienes al oír hablar por vez primera de física cuántica no se escandalizan es que no la han entendido" (como se citó en Pigem, 2013, p. 119). Lo observado, sea en las partículas subatómicas, en los procesos económicos o en la forma de entender la vida, no puede entenderse de forma independiente a quien lo observa; somos coautores y cocreadores en un pluriverso de relaciones del que, por supuesto, formamos parte.

Es de esta forma que se podría decir que lo epistemológico precede a lo ontológico - o mejor dicho no son cosas distintas, ambas forman parte del proceso dinámico que conocemos como realidad. En este sentido nuestra misma forma de ver, interpretar y nombrar la realidad crea la realidad misma que experimentamos.

Esto es lo que "descubrió" la física hace varias décadas al constatar que las partículas se comportan de modos distintos cuando son observadas que cuando no lo son. Así, Schrödinger y Wigner explicaban que la base de la realidad está en la conciencia y la percepción, y no en la materia (Pigem, 2009). Sin embargo, los budistas lo conocen desde hace más de dos milenios; el Dhammapada (cap. 1) —uno de los libros más importantes del budismo- empieza con la contundente frase: "todo lo que somos es resultado de lo que hemos pensado". La idea de sujeto (observador) y objeto (realidad observada) se desmorona, y en su lugar queda una idea de realidad participativa. Asumir esta condición participativa de la realidad me parece uno de los primeros pasos necesarios para construir alternativas.

"Autopoiesis" es un término incorporado por Humberto Maturana y Francisco Varela, para definir un sistema capaz de reproducirse y mantenerse por sí mismo (Maturana y Varela, 1979). 
La cosmovisión hegemónica ha visto durante siglos un mundo violento, de lucha y de poder alrededor suyo. Las nuevas visiones del mundo de una parte de la ciencia han descubierto una realidad participativa en la cual prevalece la cooperación sobre la competición, en los ecosistemas, los fenómenos físicos, los comportamientos animales, etc. Así, como recuerda Capra, "[...] la vida es mucho menos una lucha competitiva por la supervivencia que el triunfo de la cooperación y la creatividad" (1996, p. 254). Al darnos cuenta que todos estamos interrelacionados surge naturalmente la generosidad, la simpatía y la solidaridad (Pigem, 2009).

Estas ideas no son nuevas; sin embargo, no han logrado establecerse dentro de un marco epistemológico coherente y reconocido en el conocimiento hegemónico. Esto se puede interpretar al menos de dos formas. Una, como explica Pigem (2009), es que seguimos en la inercia de creer en una realidad material, con sus leyes universales, que es independiente de nosotros, que viene de muchos siglos atrás e impide ver otras posibilidades de ser. Es un profundo cambio paradigmático en nuestra comprensión de la realidad; el paso no es sencillo. La segunda, no menos importante, aparece al realizar una lectura estructural, o de ecología política mejor dicho, de la cuestión. El conocimiento hegemónico valida y sustenta el statu quo de la situación socioeconómica global.

Hemos realizado un repaso de algunas propuestas nacidas en su mayoría en el Norte global sobre las nuevas visiones del mundo y cómo estas tienen implicaciones ontológicas en nuestra interpretación de la realidad. Estos avances que se dan desde la tradición científica son sin duda importantes y loables, pero corren el riesgo de convertirse en la nueva verdad absoluta. No necesitamos nuevas verdades desde una tradición cultural, requerimos de un diálogo epistémico entre estas nuevas visiones del mundo postmodernas y las epistemologías de los pueblos del Sur global, culturas invisibilizadas y despreciadas por la sociedad industrial. Han resistido los embates y el despojo de la sociedad industrial y la hidra capitalista, y tienen mucho que aportarnos en estos tiempos de crisis global.

\section{Desde las epistemologías del Sur}

Los pueblos indígenas, las culturas de la Tierra y los pueblos del Sur (con pocos datos y mucha sabiduría) han desarrollado una sabiduría importante sobre cuestiones trascendentales -como el gozo, la solidaridad, la vida buena, la armonía con la naturaleza y la diversidad-. Muchos de estos movimientos encarnan ya las propuestas que se buscan y retoman en los sectores intelectuales. En el desconcierto que vivimos ante la crisis mundial de la civilización moderno-industrial estos saberes pueden aportar sin duda en la cuestión del equilibrio del mundo (Lajo, 2011). Su participación no solo es una cuestión de ética, sino de pertinencia.

Desde estos movimientos campesinos e indígenas -como los zapatistas en Chiapas, la Vía Campesina o el Movimiento de los Sin Tierra y un largo etc.- no se aboga por una alternativa solo de izquierda, sino de construcción de otros mundos que no separen sociedad y naturaleza, comunidad e individuo, espiritualidad y política. En estas nos inspiramos muchas personas que buscamos reorganizar desde abajo la vida social (Esteva, 2013b).

Las alternativas y propuestas que vienen de las epistemologías del Sur (Santos, 2009) no son nuevas: provienen del conocimiento ancestral de las civilizaciones originarias, que han sido excluidas y despreciadas por la modernidad. Así, aprender a escucharlas implica primero desaprender y dejar atrás nuestros colonialismos incorporados. Aprender a aprender de las personas ordinarias de las comunidades es más difícil de lo que se dice (Esteva, 2014), implica aprender a escuchar en otros ritmos, otras formas y otros tiempos. Es abrirnos a replantear nuestras propias ideas y preconcepciones, es aprender a escuchar y conocer de la naturaleza, de la vida, del agua, las plantas y la montaña.

En las cosmovisiones de los pueblos del Abya Yala no solo se conoce con la mente, sino también con el corazón, se sientepiensa (López, 2010). El illanar (rumiar el alma) del conocimiento andino incorpora las emociones y los instintos en el proceso de conocimiento (Lajo, 2012). Por el contrario, en la tradición occidental, como explica Feyerabend (1985), a partir de Platón se censuró el saber y el conocimiento que apelaba al sentimiento; se le hizo a un lado al considerársele sin un valor cognoscitivo.

La forma de aprendizaje indígena mesoamericana es la práctica. Así, por ejemplo, los niños no aprenden a trabajar la milpa en una escuela con pizarrones, sino haciendo y trabajando la milpa con su familia, lo mismo que el cafetal o el cultivo de su región. En la escuela andina, por ejemplo, no educan a sus hijos en lo negativo, lo prohibitivo o el castigo, sino en la afirmación, el reforzamiento de valores y el estímulo positivo (Lajo, 2010). El Allin ruay, allin yachay, allin 
munay andino -hacer bien las cosas, pensar bien, querer bien- fue traducido al español como "no seas ocioso, no seas mentiroso, no seas ladrón"; la interpretación muestra el paradigma de uno y otro lado.

Otra cuestión clave es la concepción que se tiene del territorio. Arturo Escobar narra cómo se lo explicó un mayor afrocolombiano: "tierra la tiene cualquiera, pero territorio es otra cosa, no solo es la tierra, es toda la vida, todo el mundo que la habita" (2014). La existencia de este territorio entendido por los pueblos indios mesoamericanos está asociado a la persona, y no se trata de una cuestión geográfica; es lo que subyace todas las relaciones que tenemos, como las sociales, biofísicas, naturales y sobrenaturales. Esta es una cuestión sagrada que lejos estaría de poder venderse-comprarse o explotarse porque en sus entrañas se encuentra cobre o litio. Si logramos extender nuestra mirada para comprender esto, seremos capaces de significar las luchas por la defensa del territorio de las culturas de la Tierra, campesinas e indígenas.

Para los pueblos indios mesoamericanos el territorio no se trata de una cuestión geográfica: este existe por quien lo habita (Escobar, 2014). Esto subyace a todas las relaciones que tenemos. Este territorio cohabitado por sus comunidades también tiene su espíritu. Es esta la visión viva y sagrada de la Pachamama, que es todo el cosmos como comunidad, además de naturaleza. Xuno López (2010) explica cómo desde la epistemología maya todo tiene su ch'ulel, su corazón-alma-espíritu-conciencia, desde los humanos hasta los ríos, las montañas, los minerales y la lluvia. Todo tiene su lenguaje, su corazón habla, piensa y llora, todo es sagrado y consciente ${ }^{2}$. Así, en lugar de conocer la naturaleza a partir de la dominación y el control -el sueño de Bacon de dominar la naturalezanos acercamos a aprender de ella, de su complejidad y belleza, a través de un sagrado respeto, de la cooperación y el diálogo (Capra, 1996).

Estas comprensiones del mundo se explican más fácilmente al entender que en los conocimientos andinos, por ejemplo, todo objeto o fenómeno se manifiesta en paridades opuestas y complementarias, que se deben "equilibrar" (Lajo, 2012). El principio ordenador es el par, todo es parido y es dualidad (Lajo, 2011). Vemos algo similar en el Hunab Ku maya; es la dualidad, el todo, que está unido y es indivisible.

\footnotetext{
2 Desde una comprensión como ésta es fácil entender por qué, por poner un ejemplo, en muchas celebraciones se pide permiso y perdón al bosque y al árbol por cortarlo para ser utilizado (Pigem, 2009).
}

Por su parte, la filosofía china lo concibe como el yin y yang, los opuestos complementarios e inseparables, cuyo fluir es el de por sí de la realidad y la experiencia humana.

Entiendo esta concepción como una polaridad fundacional que lleva a percibir a las cosas y al mundo como complementos, y es de donde surge orgánicamente el sujeto colectivo del que se habla la comunalidad.

"In Lak'ech / Hala Ken" dicen los mayas para saludarse: "yo soy otro tú / tú eres otro yo". O también se tiene el ya famoso Ubuntu de los originarios del sur de África: "yo soy porque somos". En estos pueblos originarios el sentido de la vida y de la sociedad tiene su base en la comunidad -que se conforma por humanos, plantas, animales, la lluvia, el viento, las montañas, los astros, seres de otros tiempos, etc. (Ceceña, 2012). Más que individuos, son sujetos colectivos, nudos de relaciones reguladas por la reciprocidad que crean una "comunalidad" basada en el caminar cerca del otro; es el apoyo entre familiares, compadres, comadres y vecinos lo que teje el nosotros (Esteva, 2013b).

Lo anterior también lo exponía Mariátegui, quien señalaba que un mundo nuevo emergería cuando los valores de cooperación y solidaridad del mundo andino fueran la base de la integración social (Marañón-Pimentel, 2012). Más que una mirada romántica, esto apunta a la construcción de ese otro Mundo basado en la solidaridad y la diversidad.

Esta forma de entender el mundo establece una relación muy distinta entre sociedad y naturaleza, entre producción y consumo, en el trabajo, el tiempo libre y el lucro. La producción y el trabajo no son males necesarios: son espacios de gozo, actos sociales, religiosos y económicos que alegran a la Pachamama y nos alimentan (Ceceña, 2012). El gozo reemplazará al deseo como la fuerza motriz de los quehaceres humanos. Cortar un árbol, hacer la comida, organizar la fiesta, cosechar o elegir la autoridad son actividades comunales, personales y sagradas a la vez; no hay actividades económicas o productivas separadas de las religiosas, políticas, sociales y familiares (Esteva, 2013b).

Ahora sí, este contexto podemos definirlo por los siguientes rasgos, no de forma exhaustiva, sino ilustrativa:

a. una realidad participativa,

b. de un conocimiento sentipensante,

c. de comunalidad, de un sujeto colectivo como base social, 
d. de una percepción espiritual del mundo, una Pachamama sagrada,

e. de reconocer su chiulel de todas las cosas,

f. de asumir la interconexión de todas las cosas,

g. de un dualismo fundacional que no separa en opuestos, sino complementarios, y

h. de la no separación de los quehaceres humanos

Con base en esto podemos entender mejor la concepción de "vida buena" de los pueblos mesoamericanos y andinos. De diferentes formas le llaman, Lekil Kuxlejal ${ }^{3}$ para los mayas, Sumak Qamaña para los aimaras, Sumaq Kawsay para los quechuas o Ñandareko para los guaranís. Schlittler (2012) y López (2010) narran cómo el Lekil Kuxlejal no es únicamente bienestar material, sino que es relación armoniosa con la vida en general, en lo social, lo ecológico y lo espiritual; es el respeto a los mayores, a las demás personas, a la Madre Tierra, a la vida. Xuno López (2010) explica que más que "respeto" -como vulgarmente se le traduce- se trata de saber recibir la grandeza y lo excelso de la Vida, con su ch'ulel de todas las cosas. Es una vida que se quiere y goza, por eso en Colombia y Ecuador le llaman también la vida querida.

Hablar del Lekil Kuxlejal es hablar de relaciones entre personas, de la naturaleza y de todos los seres. Más que un parámetro de bienestar, es una serie de principios y valores: estos son éticos ${ }^{4} \mathrm{y}$ aseguran el equilibrio y la convivencia armónica con la Pachamama (Lajo, 2010), con el cosmos. Todo esto, evidentemente, conlleva a otra comprensión de las cosas, y por tanto literalmente a otra posibilidad de realidad.

La cuestión de la "vida buena" tiene una base material e ideológica, pero es sobre todo espiritual (López, 2010). Este Lekil Kuxlejal, muy al contrario del "desarrollo", no tiene recetas, su concepción parte del reconocimiento de la diversidad de formas de vida buena. No hay modelo para ser exportado, globalizado o impuesto. Parte de abrirse hospitalariamente a la pluralidad, a la diversidad de formas de ser y existir, donde estas diferencias son reconocidas y celebradas

\footnotetext{
3 A partir de aquí, por facilidad de lectura, y por ser el caso que tenemos más cercano hablaremos de Lekil Kuxlejal en términos genéricos para estas concepciones de la vida buena, a menos que se aclare lo contrario.

4 Para que fuera un asunto ético, tendría que ampliarse la concepción de ética a la relación entre humanos, la naturaleza y otros seres.
}

(Esteva, 2009). Es por eso que este término debe utilizarse siempre en plural, como "buenos vivires" o "vidas buenas".

Entonces, consideramos que, para imaginar, sentipensar y construir alternativas dentro de esa esfera que separamos como "economía", algunas de las premisas aquí presentadas pueden ser relevantes. Podríamos imaginar otras economías que partan de la "comunalidad", la solidaridad, la reciprocidad y la cooperación como fundamento de las relaciones sociales, basadas en lo colectivo y no en lo individual. Así, una economía solidaria sentipensante es una que busca los buenos vivires y no la acumulación, que reconozca la sacralidad de nuestra Madre Tierra y al gozo como base del trabajo y los quehaceres humanos.

Sin embargo, no podemos sentarnos a "teorizar alternativamente" mientras los procesos de despojo y destrucción continúan. La teoría y la práctica no son cosas distintas, y mucho menos separadas. El reto está en plantear alternativas, procesos, proyectos, actividades humanas bajo una nueva visión de la realidad. Esto nos convoca a sumarnos al sentipensar de otras economías a través de las construcciones de alternativas cotidianas (Rauber, 2013), con la gente ordinaria, desde abajo y a la izquierda -como nos invitan los zapatistas-, y con la tierra, como complementa Escobar (2016).

\section{Sentipensando alternativas}

Partimos de problematizar algunos conceptos e ideas que en general se dan por sentado en la sociedad industrial. Después expusimos algunas propuestas que surgen desde las nuevas visiones del mundo de la ciencia y otras que han estado presentes por milenios desde las culturas del Sur y sus epistemologías. El propio repaso es ya un ejercicio que apunta a ir trascendiendo el paradigma moderno. Ahora intentaremos exponer algunas alternativas que surgen a partir de las ideas propuestas. Como hemos intentado explicar, si dislocamos los marcos teóricos a partir de los cuales hacemos nuestros análisis, las conclusiones y respuestas que obtengamos serán distintas también. La realidad responde según la lengua en la que se le pregunte (Santos, 2009).

Intentemos aterrizar estas ideas en un tema crucial para la sociedad global en los albores de este milenio: la cuestión de la sustentabilidad. Tan solo plantear la pregunta de cuántos seres humanos hay en la Tierra pone en evidencia las limitantes epistemológicas del paradigma científico moderno para abordar 
la cuestión. La altísima complejidad de la naturaleza, sus ciclos, su interrelación con la sociedad sobrepasa los marcos teóricos construidos. Los propios conceptos - de sociedad y naturaleza como esferas separadas en relación- son los que imposibilitan la comprensión y nublan la realidad.

Ante la urgencia percibida de posibles cambios ecosistémicos importantes que se avecinan nos encontramos en un abismo, sin asideros teóricos o construcciones metodológicas para comprender la cuestión. Nos preguntamos cuánto tiempo nos queda antes de que los ecosistemas puedan cambiar drásticamente de estado. ¿Qué tipos de cambios ambientales implicarán estos cambios? ¿Estamos al borde de un cambio ecosistémico global?, ¿o los sistemas son más resilientes de lo que asumimos? ¿Estos cambios son irreversibles? ¿Cuáles son sus consecuencias sociales y para las demás especies con quienes cohabitamos este hogar? ¿Podrá sobrevivir el estilo de vida de la sociedad industrial a esos cambios?

El problema de la crisis ambiental y de la sustentabilidad cuestiona la racionalidad, los soportes ideológicos y el paradigma que han impulsado este proyecto civilizatorio occidental, así como a las bases ontológicas y epistemológicas con las que la modernidad se ha lanzado a entender y comprender el ser y las cosas, el mundo. Es en este sentido que la crisis ambiental es en sí misma una crisis del conocimiento hegemónico; se ha vuelto un problema existencial (Leff, 2000). Para acercarnos a comprender la cuestión sobre la sustentabilidad tendremos que deconstruir la economía convencional y nuestra concepción y relación con la Naturaleza.

Entonces, ¿a qué nos referimos cuando hablamos de sustentabilidad?: ¿a un adjetivo, una meta, una condición o un proceso? ¿Es un concepto en sí que se pueda abstraer y definir?, ¿o es más bien un estado de ser, un modo, un punto de partida de todos los quehaceres y pensares humanos?

Al imaginar la sustentabilidad como un estado de ser -y no como un concepto o como un horizonte futuro posible- se concibe como una condición de los seres vivos en la que se priorizan los procesos que sustentan toda la vida en el planeta (en este sentido la naturaleza es sustentable per se, tanto sus procesos como ciclos mantienen y aseguran la vida, además de su diversidad en el planeta). Este es un estado de ser que implica sentipensar todos los quehaceres humanos de manera relacional, conectada y vinculada a las demás personas, así como a las especies y formas de vida; la naturaleza no es algo externo con lo cual nos relacionamos -ya sea a través de relaciones de dominación o de colaboración-, sino es una parte intrínseca de nosotros mismos y de la vida en el universo. Es la Pachamama de la que nos hablan las comunidades andinas.

Para empezar a pensar en la sustentabilidad vale la pena escuchar y aprender de la Pachamama, de cómo ha asegurado mantener la vida en el planeta: a partir de la diversidad, biodiversidad. Habrá pues que partir de reconocer, bienvenir y celebrar la diversidad en todas sus expresiones -cultural, social, epistemológica, espiritual, y de fanáticos de fútbol también-. Esta diversidad reconoce que así como no hay verdades absolutas sino múltiples, no hay un buen vivir sino buenos vivires.

Esta posibilidad abre un debate por supuesto: ¿cómo pensar la sustentabilidad asumiendo la diversidad de formas de vida y de maneras de concebir la "buena vida"? ¿Podemos incorporarla sin utilizar un criterio único y unidireccional? Me parece que para plantearnos seriamente una propuesta de buenos vivires y de sustentabilidad como un estado de ser podríamos empezar con tres premisas básicas de carácter normativo y una de carácter espiritual.

La primera implica apuntar al equilibrio dinámico de las cosas. Esto lo saben las sabidurías ancestrales orientales -así consta en el Bhagavad-Gita, el Dhammapada o el yin-yang-, pero también las tradiciones indígenas mesoamericanas -como en el Hunab Ku y el Lekil Kuxlejal- y en el Ubuntu africano (Pigem, 2009, p. 56).

La segunda característica, ligada a la primera, muestra que el modo de buen vivir de cualquier sociedad no puede ir en detrimento del de otras sociedades. Para tener una comprensión cabal de esta situación, como hemos expuesto, se requiere de otros marcos epistémicos que permitan un abordaje más robusto y una comprensión más holística y relacional de la realidad.

La tercera premisa, cuya discusión se podrá aplazar, pero de ninguna forma eliminar, va en torno a un control de la natalidad humana. Por más sostenible -en términos de utilización de materia biofísica para la supervivencia- que pueda ser una sociedad, si su número rebasa un umbral, terminará por consumir y acabar los propios insumos que la mantienen. Aquí es donde el conocimiento científico - de los sistemas complejos y disipativos- deberá de da dar un aporte importante.

La cuarta característica es de carácter espiritual. Xuno López (2010) explica que el Lekil Kuxlejal tiene su base en el ich'el ta muk', definido como la 
experiencia y la aspiración a lo excelso de la bondad y la abundancia -no en términos materiales de tener más cosas-. Siguiendo a López, si reconocemos la ch'ulel -alma, espíritu- de todas las cosas, la vida buena consiste en una relación armónica con la Pachamama, con el cosmos y con todas las formas de vida.

Esta característica es la que celebra la diversidad en el mundo, posiblemente a través de un panteísmo,que reconoce y sabe recibir tanto excelso como la grandeza de la vida. Partiendo de tal postura el camino hacia la sustentabilidad ya no se entiende como una cuestión de límites, de restricciones y de control en el camino del desarrollo, sino como el camino en sí hacia la vida buena construida con base en buenos quehaceres humanos.

A la par habrá que ir imaginando nuevos marcos teóricos que den sustento a estas alternativas en construcción. En el camino de la economía consideramos que hay cuatro corrientes complementarias con las cuales podríamos armar un marco de referencia congruente: la ecología política y la decolonialidad del poder por un lado, y la economía solidaria y la economía ecológica por el otro.

Víctor Toledo (2015) afirma que la lectura política y sistémica de la ecología política nos puede guiar para comprender mejor el desplazamiento del mundo hacia el caos que estamos atestiguando. Por otro lado la decolonialidad del poder asume esa misma mirada sistémica. Me parece que la construcción de alternativas debe partir de un enfoque como el que desde estas ramas se plantea: complejo, relacional, ecológico y político.

Por su parte, la economía ecológica propone una mirada sistémica y coevolutiva de la realidad, poniendo énfasis en lo relacional. Si bien sus marcos metodológicos siguen enraizados en el paradigma newtoniano, se ha intentado superar las simplificaciones monetarias a partir de la inclusión de la base material y biofísica en sus flujos. Finalmente, la economía solidaria da un paso en otra dirección al modificar su sujeto de estudio. La economía convencional supone que el ser humano es un hombre racional, egoísta, individualista, ambicioso, siempre insatisfecho y desvinculado de su espíritu, de sus sentimientos, de su comunidad y de la misma naturaleza. La economía solidaria se abre a un ser humano mucho más complejo que parte del sujeto colectivo, que es solidario y comunitario.

Estas cuatro corrientes son complementarias, y ponerlas en diálogo nos permite imaginar un posible marco de economía ecológica y solidaria en construcción. Cambiando los axiomas de los cuales partimos, los resultados de nuestros análisis serán distintos. La realidad se comporta de manera distinta según sea observada, como hemos defendido antes. El reto aquí está en construir las propuestas técnicas y metodológicas, ya que la inercia pasiva de la economía convencional (cuyas bases epistémicas y analíticas siguen siendo las de la economía neoclásica del s. xviII) es muy grande.

Propuestas alternativas como las pocas aquí discutidas están en construcción en todas partes del mundo. No tienen los reflectores de los medios sin duda, pero son procesos organizados que buscan modos alternativos de hacer las cosas en todos nuestros quehaceres humanos, de la salud a la política, a la producción y alimentación.

Este ejercicio no pretende defender ni idealizar estas propuestas, sino intenta exponer que, a partir de la dislocación los marcos de referencia habituales y partiendo de un diálogo con los saberes del Sur y con las nuevas visiones del mundo, podemos caminar hacia un pensamiento alternativo, desde el sentipensar, para pensar e imaginar las alternativas. Andar este camino implica enfrentarnos a vacíos teóricos y a la ausencia de métodos y formas para abordar los temas. Es abrir brecha en la selva y asumir el riesgo a perderse; pero tal vez perdiéndonos nos encontremos.

\section{De cómo intentamos hacerlo en Yomol A’tel (Chiapas, México)}

Yomol A'tel ${ }^{5}$ es un grupo de cooperativas y empresas de economía solidaria ubicado en la Selva Norte de Chiapas, México. Lo forman más de 350 familias, de 66 comunidades indígenas tseltales y 76 trabajadoras, trabajadores y colaboradores. Nuestro objetivo es construir procesos integrales de economía solidaria, para con esto asegurar los medios de subsistencia para todos nuestros cooperativistas. Nos organizamos a partir del trabajo y apostamos por la construcción de nuestro Lekil Kuxlejal, por la defensa de nuestra Madre Tierra, del territorio y la cultura tseltal.

Estamos en nueve regiones en Chiapas, en la Ciudad de México, Puebla y Guadalajara. Trabajamos con café comercializándolo tostado en bolsa y en

A'tel en tseltal significa trabajo y Yomol algo similar a organización. Pero la definición que pensamos del nombre es "juntos trabajamos, juntos caminamos, juntos soñamos". 
taza; con miel y sus derivados; en microcréditos, y en pequeños emprendimientos productivos en el ámbito comunitario o regional. Nuestra estrategia es apropiarse de los procesos de valor agregado de nuestros productos y los procesos financieros que los posibilitan. La cooperativa Ts'umbal Xitalha' ("el Ts'umbal -espacio organizativo tseltal- de Sitalá") fue donde empezó todo, en una comunidad y 22 productores. Hoy en día hemos dejado de ser proveedores de materias primas, comercializamos productos terminados de calidad en México, EE. uU. y España.

En este proceso productivo y "empresarial" intentamos partir de las bases de la economía solidaria, que pone en el centro a la persona y no al capital, y de la cosmovisión tseltal basada en la solidaridad, la comunalidad y una visión sagrada de la Madre Tierra. Así, las relaciones humanas e interorganizacionales se procuran basar en la solidaridad y la confianza. En lugar de ver relaciones competitivas e individualistas - con proveedores, clientes, empleados u otras organizaciones- buscamos entenderlas como colaborativas y solidarias.

Con base en la apropiación del proceso de valor agregado del café (tostado, comercialización y venta en taza) se ha logrado la "construcción del precio". Esto es que hemos podido desprendernos de red de coyotaje, sujeta a la imposición del mercado en Nueva York, que explota y denigra a las familias productoras $^{6}$. El café en los últimos tres años se ha pagado a un precio fijo -determinado por el propio grupo Yomol A’tel- y según la calidad del grano, mientras que el precio de coyotaje varía siguiendo una lógica de las materias primas de la bolsa de valores. Esto se aprecia en la siguiente gráfica.

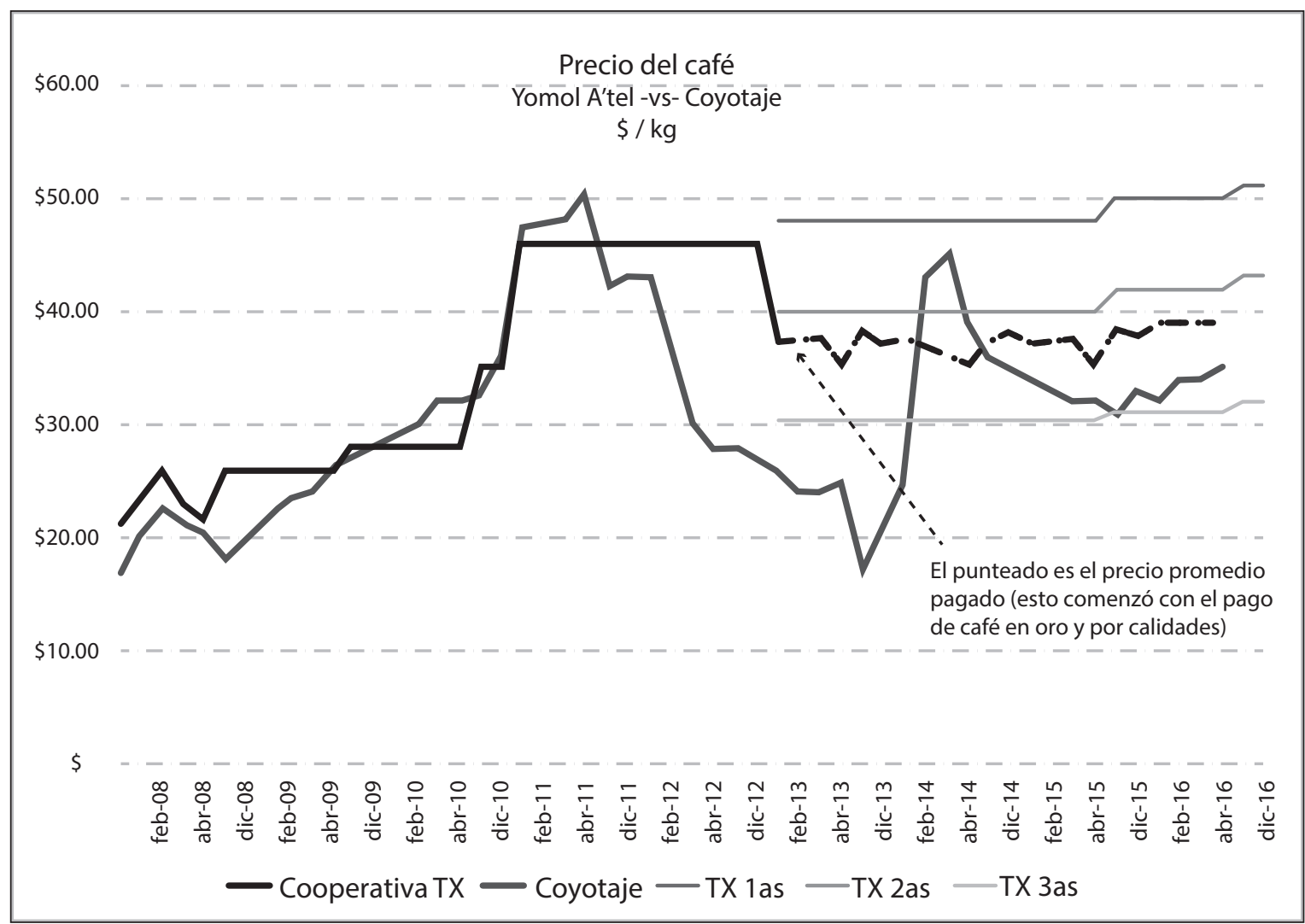

Figura 1. Comparativo del precio del café en la Región Selva Norte de Chiapas.

Fuente: elaboración propia.

$6 \quad$ Coyotes se les llama a los intermediarios locales de café, quienes acopian, en su gran mayoría, para empresas trasnacionales, y quienes son los únicos que les prestan el dinero necesario para el acopio a las familias productoras, cobrando tasas de alrededor del 15\% de interés mensual, entre otras prácticas de despojo, como las básculas mal calibradas o engañar a los productores con el precio "del mercado". 
Esta construcción del precio se sostiene gracias a la apropiación de la cadena de valor. Por un lado, esto se hace con las ventas de Bats'il Maya ("maya verdadero"), empresa solidaria del grupo que comercializa alrededor de 100 toneladas de café al año. Por otro lado, se realiza a través de la venta en taza de Capeltic ("nuestro café") -compuesta por cinco cafeterías en universidades de México- donde intentamos ser no solo un punto de venta, sino un puente intercultural entre la comunidad universitaria y las comunidades tseltales de Chiapas.

El camino de la cadena de valor de la miel va por el mismo rumbo pero ha sido más lento. Sin embargo, estamos en el proceso de desarrollar productos de valor agregado de la miel -como dulces y alimentos, y productos de higiene como jabones y cremas, proceso que lleva la cooperativa de mujeres Yip Ants'etic ("fuerza de las mujeres")-.

El fondo de la microfinanciera Comon Sit Ca'teltic ("el fruto de nuestro trabajo en común") se hizo con las aportaciones de las familias productoras en el 2012 y el 2013, años en los que el café de la cooperativa llegó a estar a más del doble de los precios locales. Este proceso financiero surge por la necesidad de salirnos de las prácticas injustas y desleales de los coyotes. Con estas aportaciones se han otorgado más de 120 créditos - de salud, alimentación, trabajo, educación y fiesta, a una tasa del $2 \%$ mensual, decidida por los representantes de la cooperativa-. El 2016 comenzamos con los créditos para pequeñas iniciativas productivas comunitarias y regionales. El fondo se seguirá creciendo con los intereses de esos préstamos y con los excedentes que se vayan teniendo cada año en Yomol A'tel.

De esta forma -a través de la apropiación del valor agregado y de los procesos financieros que lo posibiliten- buscamos asegurar un ingreso económico autogestionado que permita la subsistencia de nuestras familias. Ahora el camino nos ha llevado a contar con excedentes económicos y nos encontramos en proceso de constituir diferentes fondos sociales para atender nuestros problemas de salud, educación, transporte, emprendimientos productivos, etc. Ahora pensamos que no se trata solo de tomar los medios de producción y transformación, sino de lograr un ciclo económico completo, en el que el retorno de los excedentes $-\mathrm{a}$ los cooperativistas, productores y trabajadores- cierra el ciclo.

Decían los fundadores de Grupo Mondragón que se trataba no tanto de crear cooperativas, sino de formar cooperativistas: ellos ya formarían sus procesos organizados con cooperativas $u$ otras formas organizativas. En este sentido en Yomol A'tel comprendemos a las distintas unidades de trabajo como escuelas, no como escuelas de aulas y pizarrones, sino bajo el esquema tseltal de aprender haciendo. Los hijos de productores de las nueve regiones del Ts'umbal Xitalha' realizan servicio en distintas áreas de trabajo -planta de café y de miel, administración, trabajo agroecológico, etc.- y se van formando en estos procesos. Poco a poco ellos son los que empiezan a activar los Módulos Integrales de Yomol A’tel regionales (MIYA's), en los cuales se realizan procesos productivos de valor agregado - como el beneficio húmedo del café, la producción de jabones con base de miel, microcréditos productivos, etc.

A este proceso lo llamamos "escuela para la sustentabilidad". Desde la práctica todos vamos aprendiendo y enseñando diferentes cosas -técnicas, administrativas, contables, sociales, culturales, rituales, agroecológicas, espirituales, etc.- intentando no separar lo económico de lo espiritual, lo productivo y lo empresarial. Intentamos construir esto como un espacio de aprendizaje autónomo que responda a las necesidades propias de las personas que participamos en este Yomol A'tel.

No entendemos el trabajo como en la sociedad industrial, como algo que se tiene, como un mal necesario. Para la mayoría de las comunidades indígenas mesoamericanas el trabajo no se tiene, se hace. Desde esta comprensión de trabajo se basan mis compañeros tseltales de Yomol A’tel, concepción que los que venimos de fuera vamos lentamente aprendiendo.

Finalmente lo que buscamos es construir relaciones solidarias, comunales, cooperativas en lo humano y lo económico. Para ello se debe asumir que estas relaciones no pueden surgir de la eficiencia competitiva, sino de la solidaridad y de lo que antes se intentó exponer. Pero lograr mantener este proceso sin la participación en el mercado y la competencia global es muy difícil, y tampoco buscamos prescindir de ello. Confiamos en que dentro de ese sistema despiadado también podemos construir relaciones de solidaridad y de confianza. Así, k’un k’un -“despacio, despacio", como dicen allá- podemos ir construyendo esas otras economías al interior de la existente?

Así pensamos que propuestas cooperativistas como esta no deben ser entendidas ni juzgadas como las alternativas en sí, sino como pasos intermedios en la construcción de esos otros mundos, pasos que permitan, primero, la subsistencia de nuestros pueblos. Cuidando siempre que en este quehacer se vayan construyendo esas nuevas formas de relación social y humana. 
Aunque contarlo aquí es sencillo, la práctica lo es mucho menos. Todos cargamos con hábitos y modos importados del pensamiento hegemónico que complican este intento. Sin embargo, suponemos, como explica Isabel Rauber (2013), que será muy difícil contar con las teorías de otras economías antes de contar con las prácticas que las sustenten. Es decir, que los modelos de otras economías surgirán a partir de las experiencias alternativas de producción y de construcción de otras formas de hacer economía. Es en estas experiencias en las cuales convive contradictoriamente lo viejo y lo nuevo; así es la búsqueda, así es el aprendizaje.

En estas épocas el pesimismo se apodera de las mentes impacientes, y la ausencia de rupturas completas a partir de los procesos de economía solidaria genera escepticismo, pero no podemos esperar que estas construcciones generen transformaciones profundas de la sociedad en el corto plazo (Santos y Rodríguez, 2002). No perseguimos estos cambios en el corto plazo. ¿Qué tan profundos asumimos los cambios que requerimos? La nueva organización económica no es sólo una tarea intelectual, supone también una serie de cambios profundos en nuestro interior, nuestra concepción del mundo y nuestro sistema de valores (Capra, 1982). ¿Se trata solo de construir otra economía o de construir otra sociedad (Marañón-Pimentel, 2012)?

\section{Algunas reflexiones, por no dejar}

Tal vez la mejor palabra para definir a la humanidad -o mejor dicho a la sociedad industrial globalizada- del siglo xx sea la de plaga. Antes de que nadie se ofenda veamos cómo la define la Real Academia Española: "aparición masiva y repentina de seres vivos de la misma especie que causan graves daños a poblaciones animales o vegetales". El chiste se cuenta solo.

En estos tiempos de crisis "[...] no es simplemente un conocimiento nuevo lo que necesitamos; necesitamos un nuevo modo de producción de conocimiento. No necesitamos alternativas, necesitamos un pensamiento alternativo de las alternativas" (Santos, 2006, p. 16). Por supuesto no es tarea sencilla, los cambios de época se dan durante muchas décadas. Quienes quieren soluciones prontas recurren a los marcos teórico-conceptuales existentes renunciando a la posibilidad de buscar fuera de lo construido. Las alternativas que buscamos, y necesitamos, no existen ni están ahí esperando a que vayamos a tomarlas. Hay que construirlas, teorizarlas, senti-pensarlas, practicarlas y existirlas.

En medio de esta crisis global, constatamos tiempos de cambios y de inicios (pensado en una larga escala de tiempo) que surgen del derrumbamiento del ego moderno y su interpretación moderna y materialista de la realidad. Como explica Gustavo Esteva (2014), nuestra lucha, más que contra este sistema opresor, es contra esta mentalidad moderna que nos ha dominado y nos corroe por dentro.

Este camino es más complicado porque el sistema que se cae a pedazos no cae allá afuera, sino sobre nosotros y con base en el despojo de nuestros pueblos. Resistir y luchar contra este sistema es algo imprescindible, pero no suficiente. Esta resistencia solo valdrá la pena si en su proceso va construyendo la forma alternativa de lo que sí se quiere en este mundo. Además, únicamente así tendrá futuro, ya que esta forma capitalista dominante no dejará de existir hasta que se hayan construido las formas de organización social que la sustituirán (Esteva, 2013b).

Siguiendo las ideas del mismo Esteva (2014), más que luchar por derrumbar este sistema y sus estructuras opresoras, como lo intentaron las revoluciones tradicionales, habrá que construir los procesos autónomos que las conviertan en obsoletas: así perderán su sentido y su capacidad opresora sobre nosotros. Se trata de convertir la lucha de los sustantivos (como educación, salud o trabajo) en una construcción de los verbos (como aprender, sanar o trabajar). Los sustantivos nos colocan en una posición pasiva, que recibe, mientras que los verbos -las acciones- nos regresan a la posibilidad de conseguirlos, con nuestros medios y formas. De esta forma las estructuras que otorgan esos derechos y servicios van perdiendo su capacidad de opresión.

Esta construcción de pequeños espacios liberados puede darse en cualquier lugar donde estemos parados; es justo en el seno de la vieja sociedad donde podemos crear nuevas formas de relaciones sociales (Esteva, 2009). La cuestión no es dónde intentamos generar los cambios, sino cómo lo hacemos. Por ejemplo, incluso desde las propias instituciones oficiales del Sur podríamos romper los esquemas desarrollistas planteando y ofreciendo algo similar a una "ayuda oficial para la vida buena" Sur-Norte, en contraparte a su tramposa "ayuda oficial para el desarrollo" norte-sur. Se podría reconocer - como propone la "Carta de la transdisciplinariedad" (1994) - el derecho de ser habitantes de la Tierra, tener así una doble pertenencia, a una nación y a la Tierra. 
Así como la ONU (1986) declaró el “derecho al desarrollo", hoy los pueblos del Sur exigimos nuestro "derecho al no desarrollo" y a que se respeten las concepciones de vida buena y de buenos vivires que desde las culturas de la Tierra se tienen. Las epistemologías del Sur, por derecho propio y por sus pertinentes propuestas ante esta crisis mundial, tienen mucho que aportar. Ese otro mundo que soñamos no será un universo utópico, sino un pluriverso de heterotopías de otros mundos posibles. En palabras más sencillas lo explican los zapatistas:

$<$ Inicio de cita> y si la banda sonora de esta película tiene ritmo de polka-balada-corrido-ranchera-cumbia-rock-ska-metal-reggae-trova-punkhip-hop-rap-y-los-que-se-acumulen no es porque no tengamos noción musical. Es porque esa casa tendrá todos los colores y todos los sonidos. Y habrá entonces miradas y oídos nuevos que comprenderán nuestro empeño... (EZLN, 2013). <Fin de cita >

Este proceso de construcción de alternativas diversas debe asumirse desde una postura política sí, pero sobre todo espiritual. Esto nos invita a asumir que los cambios que requerimos no se tienen que dar allá "afuera", sino dentro de nosotros. Sin una transformación espiritual, sin un cambio en nuestra conciencia, nada lograremos; a lo mucho podremos crear versiones modificadas del mismo mundo una y otra vez (Tolle, 2005).

Ya Gandhi decía "sé el cambio que quieras ver en el mundo", e Iván Illich lo expresaba en términos de convertirnos en ejemplos de la era que deseamos crear. El llamado es a vivir en carne propia el cambio que deseamos ver en el mundo. Nuestras luchas solo tendrán sentido en la medida que asumamos que la lucha es contra nuestra concepción parcial de la realidad -contra este ego moderno- y más allá, que asuman que el reto es construir alternativas a partir de la resistencia. El cambio que veremos en ese mundo externo será una consecuencia de este cambio interior.

Así pues, para terminar, dos ideas que me parecen importantes para las luchas y construcciones que realizamos. La primera es que los cambios que buscamos y soñamos ver en todo el mundo no van a llegar en el corto plazo. Es muy difícil cambiar la inercia de una visión del mundo que se ha expandido e impuesto en los últimos siglos. Esto invita a las mentes impacientes a la desazón y la desesperanza, a luchar precipitadamente desde la rabia y la ira contra ese sistema que está destruyendo la vida en el planeta.

Pero esta forma de resistencia nos va desgastando y amargando, nos hace infelices y nos convoca a ver el mundo a partir del odio, la destrucción, la violencia, la escasez, el despojo y la opresión. Esta aproximación epistemológica, como hemos intentado mostrar, nos lleva a darle más realidad y a perpetuar esa situación contra la que luchamos. También nos lleva a perder nuestros últimos bastiones de libertad: nuestro derecho al gozo, la felicidad y el placer de la vida. Pero la libertad, como la dignidad, no se pide: se asume. Para esto habrá que tomar una postura que parta del gozo, del disfrute, del amor, de la sacralidad del mundo y la celebración de la vida. En tiempos como estos, conservar la sonrisa, el gozo, la alegría y el amor al mundo son actos de asumida rebeldía. Este cambio es, en mi opinión, una de las descolonizaciones pendientes más importantes por realizar.

Hace varios años los zapatistas expresaban que cambiar el mundo era muy difícil, quizá imposible, pero lo que sí podríamos hacer era construir un mundo nuevo. Como ellos, miles de movimientos en el mundo han ido manteniendo y construyendo, desde hace siglos, otros mundos, otras formas: los suyos, los invisibilizados. Esta es la segunda y última idea. Ese otro mundo posible que queremos construir no está en el futuro: ya existe, aunque está lejos de la atención de los medios de paga. Cientos, o miles, de millones de personas en el mundo están viviendo ese otro mundo hoy mismo -la mayoría de ellos en el Sur- que muchos de nosotros seguimos imaginando en un futuro que nunca termina por llegar.

El mundo ya cambió, ya nació el nuevo mundo. Ya existen nuevas relaciones sociales y hay una nueva conciencia. Gustavo Esteva (2013a) narra cómo los primeros burgueses y proletarios murieron sin saber que ya lo eran, sin haberse dado cuenta que ya estaban bajo relaciones sociales propias del capitalismo. Seguían teniendo su mentalidad en el pasado pensando en el rey y el régimen feudal. No lograron ver que ya se había creado un nuevo régimen social de producción. No podemos dejar que nuestra mente moderna, siga aventando ese otro mundo a un futuro nunca presente.

Este mundo nuevo por supuesto que está "contaminado" por las prácticas del paradigma que se derrumba, pero ya está aquí. Nuestra primera tarea es destaparnos las orejas para escuchar y abrir bien los ojos para ver y reconocernos en ese nuevo mundo que ya nació desde las entrañas del viejo; el primer reto es a vernos, escucharnos y reconocernos (Esteva, 2013a).

Esto sabemos y sentipensamos. Para poder mirar ese mundo externo hay que ajustar nuestra mirada, nuestro conocimiento y nuestros valores, no en 
un ejercicio teórico desapegado de la realidad, sino a partir de lo que hacemos, en donde lo hagamos. Como decía Galeano, al fin y al cabo, somos lo que hacemos, para cambiar lo que somos.

Porque lo que creemos y vemos que existe no agota las posibilidades de la existencia. Este camino será marcado pues por un diálogo epistémico-ontológico con esta realidad participativa. Ese otro mundo posible será, y ya es, fruto de un cambio en nuestra conciencia.

\section{Referencias}

Capra, F. (1975). El Tao de la Física. Barcelona: Sirio.

Capra, F. (1982). El Punto Crucial. Buenos Aires: Editorial Troquel.

Capra, F. (1996). La trama de la vida: una nueva perspectiva de los sistemas vivos. Barcelona: Anagrama.

"Carta de la Transdisciplinariedad, Convento de Arrábida”. (Noviembre de 1994). Recuperada de: http://iibi. unam.mx/archivistica/transdisciplinariedad_carta. pdf.

Ceceña, A. (2012). Dominar la naturaleza o vivir bien: disyuntiva sistémica. Debates Urgentes, (1), 117-129.

Dhammapada: por el sendero de Buda (ed. 2009). México D.F.: Editorial Tomo.

Escobar, A. (1995). Encountering Development. Princeton: Princeton University Press.

Escobar, A. (2014). “Territorios de la Diferencia: la dimensión ontológica de las Epistemologías del Sur". En Coloquio Epistemologías del Sur, CES, Universidad de Coimbra.

Escobar, A. (2016). Desde abajo, por la izquierda, y con la Tierra: La diferencia de Abya Yala-Afro-Latino-América. Recuperado de: http://pueblosencamino.org/?p=2213.

Esteva, G. (1992). Desarrollo. En W. Sachs (ed.), Diccionario del desarrollo: una guía del conocimiento como poder (pp. 52-77). Perú: Pratec.

Esteva, G. (2009). Más allá del desarrollo: la buena vida. América Latina en Movimiento, 33(2), 1-5.

Esteva, G. (2013a). Ponencia presentada en el 3er Seminario Internacional de Reflexión y Análisis "Planeta Tierra: Movimientos Antisistémicos". CIDECI-Unitierra. San Cristóbal de las Casas, México.

Esteva, G. (2013b). To Rethink the Economy from an Indigenous Experience. The Latin American Agenda.
Esteva, G. (2014). Crianza mutua y buen vivir: más allá de la educación y el desarrollo. Día de la Comunidad Solidaria 2014. Guadalajara: Iteso.

Feyerabend, P. (1984). Adiós a la razón. Madrid: Tecnos.

Feyerabend, P. (1985). ¿Por qué no Platón? Madrid: Tecnos.

Georgescu-Roegen, N. (2007). Ensayos bioeconómicos. O. Carpintero (Ed.). Madrid: Los Libros de la Catarata.

Happy Planet Index: 2012 Report. A global index of sustainable well-being. London: New Economics Foundation.

Illich, I. (1973). La convivencialidad. México, D.F.: Fondo de Cultura Económica

Illich, I. (1992). Necesidades. En W. Sachs (ed.), Diccionario del desarrollo: una guía del conocimiento como poder (pp. 157-175). Perú: Pratec.

Lajo, J. (2010). Sumaq Kawsay-ninchik o nuestro Vivir Bien. Revista de Integración de la Comunidad Andina, (5), 112-125.

Lajo, J. (2011). La sabiduría de nuestros pueblos puede dar muchas sorpresas (entrevista por Gustavo Pablos). Recuperado de http://www.goethe.de/ins/ar/cor/prj/bic/ vo3/es6623921.htm

Lajo, J. (2012). Illanar: facultad andina que supera el "razonar". Recuperado de: http://migrantelatino. com/2012/11/07/javier-lajo-illanar-facultad-andina-que-supera-el-razonar/.

Leff, E. (1996). La insoportable levedad de la globalización: La capitalización de la naturaleza y las estrategias fatales de la sustentabilidad. Revista Universidad de Guadalajara, (6), 21-27.

Leff, E. (2000). Tiempo de sustentabilidad. Ambiente \& Sociedade, 6(7), 5-13. http://dx.doi.org/10.1590/s1414$753 \times 2000000100001$

López, X. (2010). Ich’el ta muk’: la trama en la construcción del lekil kuxlejal. Hacia una hermeneusis intercultural o visibilización de saberes desde la matricialidad del sentipensar-sentisaber tseltal. En El Otro Bicentenario. México, D.F.: Red-IINPIM AC.

Marañón, B. (2012). La colonialidad del poder y la economía solidaria. En B. Marañón (ed.), Solidaridad económica y potencialidades de transformación en América Latina; una perspectiva descolonial (pp. 21-58). Buenos Aires: Clacso.

Maturana, H. y Varela, F. (1979). Autopoiesis and Cognition: The Realization of the Living. Boston: Springer.

Morin, E. (1993). El desafío de la globalidad. Archipiélago: Cuadernos de Crítica de la Cultura, 16, 66-72. 
ONU. (1986). Declaración sobre el derecho al desarrollo. Acuerdo de la Asamblea General de las Naciones Unidas el 4 de diciembre de 1986.

Pigem, J. (2009). Buena crisis: hacia un mundo postmaterialista. Barcelona: Kairós.

Pigem, J. (2013). La nueva realidad: Del economicismo a la conciencia cuántica. Barcelona: Kairós.

Rauber, I. (2013). En busca de una economía para el bien común. América Latina en Movimiento, 32(2), 7-9.

Rist, G. (2002). El desarrollo: historia de una creencia occidental. Madrid: Los Libros de la Catarata.

Sachs, Wolfgang (1990). The Archeology of the Development Idea. Montreal: Intercultural Institute of Montreal.
Santos, B. (2000). Crítica de la Razón Indolente: contra el desperdicio de la experiencia. Bilbao: Desclée de Brouwer.

Santos, B. (2009). Una epistemología del Sur: la reinvención del conocimiento y la emancipación social. México D.F.: Siglo XXI.

Schlittler, J. (2012). ¿Lekil Kuxlejal como horizonte de lucha? Una reflexión colectiva sobre la autonomía en Chiapas (tesis). Ciesas, Chiapas, México.

Toledo, V. (2015). Caos global y ecología política. La Jornada. Recuperado de http://www.jornada.unam. $\mathrm{mx} / 2015 / 02 / 03 /$ opinion/016a2pol

Tolle, E. (2005). Una nueva tierra. México, D.F.: Norma. 